\title{
Repression of Septin9 and Septin2 suppresses tumor growth of human glioblastoma cells
}

\author{
Dongchao Xu', Ajuan Liu', Xuan Wang ${ }^{1}$, Yidan Chen ${ }^{1}$, Yunyun Shen ${ }^{2}$, Zhou Tan ${ }^{1}$ and Mengsheng Qiu ${ }^{1,3}$
}

\begin{abstract}
Glioblastoma (GBM) is the most common primary malignancy of the central nervous system (CNS) with $<10 \% 5$-year survival rate. The growth and invasion of GBM cells into normal brain make the resection and treatment difficult. A better understanding of the biology of GBM cells is crucial to the targeted therapies for the disease. In this study, we identified Septin9 (SEPT9) and Septin2 (SEPT2) as GBM-related genes through integrated multi-omics analysis across independent transcriptomic and proteomic studies. Further studies revealed that expression of SEPT9 and SEPT2 was elevated in glioma tissues and cell lines (A172, U87-MG). Knockdown of SEPT9 and SEPT2 in A172/U87-MG was able to inhibit GBM cell proliferation and arrest cell cycle progression in the $S$ phase in a synergistic mechanism. Moreover, suppression of SEPT9 and SEPT2 decreased the GBM cell invasive capability and significantly impaired the growth of glioma xenografts in nude mice. Furthermore, the decrease in GBM cell growth caused by SEPT9 and SEPT2 RNAi appears to involve two parallel signaling pathway including the p53/p21 axis and MEK/ERK activation. Together, our integration of multi-omics analysis has revealed previously unrecognized synergistic role of SEPT9 and SEPT2 in GBM, and provided novel insights into the targeted therapy of GBM.
\end{abstract}

\section{Introduction}

Glioblastoma (GBM), which starts in the brain and spine with approximately 210,000 new diagnoses per year around the world ${ }^{1}$, account for $81 \%$ of primary malignant brain tumors ${ }^{2}$. According to their origins, there are three types of gliomas including astrocytic tumors (World Health Organization classification astrocytoma grades I, II (astrocytoma), III (anaplastic astrocytoma), and IV (GBM)), oligodendrogliomas, ependymomas, and mixed gliomas ${ }^{3}$. Although it has been 90 years since it was

\footnotetext{
Correspondence: Zhou Tan (tanzhou@hznu.edu.cn) or

Mengsheng Qiu (m0qiu001@yahoo.com)

${ }^{1}$ Institute of Life Sciences, Key Laboratory of Organ Development and

Regeneration of Zhejiang Province, College of Life and Environmental Sciences, Hangzhou Normal University, Zhejiang 311121, China

${ }^{2}$ Institute of Cognitive Neuroscience and Department of Psychology, Zhejiang

Sci-Tech University, Hangzhou, China

Full list of author information is available at the end of the article

These authors contributed equally: Dongchao Xu, Ajuan Liu.

Edited by A Stephanou
}

termed by Percival Bailey and Harvey Cushing. GBM is still difficult to treat and has a poor prognosis with the median survival of about 1 year among patients ${ }^{4,5}$. Despite the advances in safe resection, radiation therapy, and chemotherapy, the remaining GBM cells generally continue to grow and become drug resistance ${ }^{6,7}$. Thus, more effective and targeted treatment strategies are required based on improved and comprehensive understanding of the molecular pathophysiology of the GBM.

Although the molecular mechanisms remain largely elusive, a large amount of GBM transcriptomic data has been accumulated around the world in the past 10 years $^{8-10}$. Due to its complexity, an adequate description of GBM system requires the combination of various molecular biological data from RNA to protein level ${ }^{11}$. Therefore, multi-omics approach aimed at integrating quantitative data of different biological molecules is necessary for discovery of key GBM molecules that are fundamental to regulate the GBM

\section{(c) The Author(s) 2018}

(c) (i) Open Access This article is licensed under a Creative Commons Attribution 4.0 International License, which permits use, sharing, adaptation, distribution and reproduction in any medium or format, as long as you give appropriate credit to the original author(s) and the source, provide a link to the Creative Commons license, and indicate if changes were made. The images or other third party material in this article are included in the article's Creative Commons license, unless indicated otherwise in a credit line to the material. If material is not included in the article's Creative Commons license and your intended use is not permitted by statutory regulation or exceeds the permitted use, you will need to obtain permission directly from the copyright holder. To view a copy of this license, visit http://creativecommons.org/licenses/by/4.0/. 
progression and provide potential targets for GBM treatments. Due to its multiform and gradual drug resistance, it is usually unrealistic that a single target could be enough to treat multifactorial tumors such as $\mathrm{GBM}^{12,13}$. Therefore, there is a strong rationale for developing multi-target therapies for $\mathrm{GBM}^{14,15}$. In light of these considerations, we applied an unbiased multi-omics method for integrating results from microarray multiplex analysis and proteomic identification analysis. This combinatory approach revealed two novel GBM-related molecules, Septin9 (SEPT9) and Septin2 (SEPT2).

Septins are a family of highly conserved GTPbinding and membrane-interacting proteins from yeast to human ${ }^{16-18}$, which are involved in various cellular processes such as cytoskeleton organization, cytokinesis, and membrane dynamics ${ }^{19-21}$. By now, 13 functional Septin genes (SEPT1 to SEPT12 and SEPT14) have been identified in human ${ }^{22}$, which can be further divided into four subgroups based on their sequence homologies (SEPT2, SEPT3, SEPT6, SEPT7 subgroup $)^{23}$. The Septin family members can mutually form apolar tri-, hexa-, or octameric complexes with strong affinity ${ }^{24}$, implying their functional interactions. However, the significance and mechanisms of their interactions are poorly understood. In addition, Septins have also been suggested to participate in a variety of cellular functions such as chromosome segregation, DNA repair, cell polarization, migration, and apoptosis ${ }^{25-27}$.

Currently, numerous studies have reported that misregulation of Septin expression or activity is associated with human tumorigenesis ${ }^{28}$. High levels of expression of five Septins (SEPT2, 7, 8, 9, and 11) were detected in breast cancer ${ }^{29-31}$. Among them, SEPT9 was identified as an oncogene in breast, ovarian, head and neck, prostate, and colorectal cancers ${ }^{32-35}$. SEPT2 downregulation was shown to suppress hepatoma cell growth by PPAR $\gamma$ (Peroxisome proliferator-activated receptor gamma) activation $^{36}$. In this study, we identified SEPT9 and SEPT2 as GBM associate genes in our multi-omics analysis, and found that suppression of their expression in GMB cells can repress the pathogenesis and progression of GBM both in vitro and in vivo.

\section{Materials and methods}

\section{Integrated multi-omics analysis}

Four previous GBM transcriptomic studies ${ }^{37-40}$ were selected based on the following criteria: (1) two types of comparable samples, primary tumor tissues, and normal controls were included; (2) more than five cases vs. controls were used; (3) experiments were run on the same platform (Affymetrix Human Genome U133 Plus 2.0 array); (4) the studies were conducted by independent groups (Supplementary Table S1). In parallel, proteomic profiling of three different GBM cell lines was performed to represent gene expression at protein level. As shown in

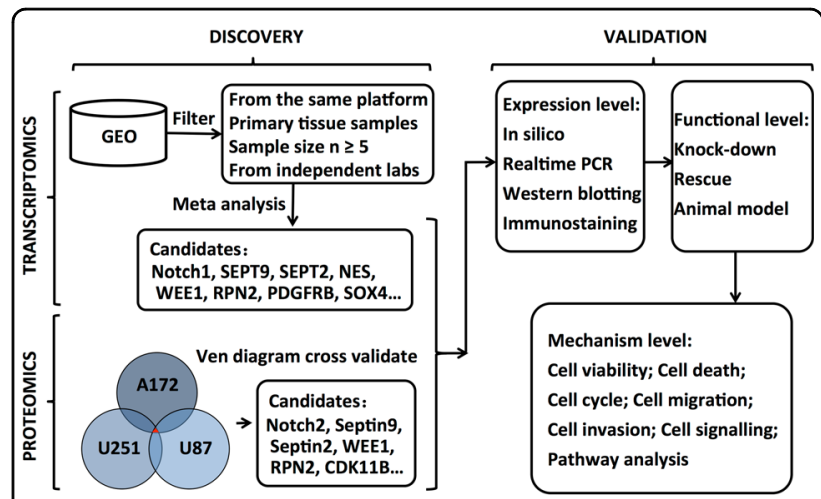

Fig. 1 Study outline of integrated multi-omics based discovery and validation of GBM associate genes. The transcriptomic analysis was based on four independent GBM studies, and the proteomic analysis was derived from three different GBM cell lines

the sketch of multi-omics analysis workflow (Fig. 1), our study was performed in two phases: (1) the discovery phase, the inputs are the data generated with both proteomic and transcriptomic studies, whereas the output is high-quality functional gene candidates ranked with respect to different statistical criteria; (2) the validation phase, which comprised in silico and experimental evaluation of the gene candidates.

\section{Antibodies and cell culture}

Anti-SEPT9, anti-SEPT2, anti-p53, and anti-p21 antibodies were obtained from Abcam (Abcam, Cambridge, MA, USA). Anti-GAPDH (Glyceraldehyde 3-phosphate dehydrogenase) mouse $\mathrm{mAb}$ was obtained from Millipore (Millipore, Hayward, CA, USA). Anti-phospho-MEK1/ 2 (Mitogen-activated protein kinase kinase 1/2), antiErk1/2 (Extracellular signal-regulated kinase), anti-phospho-Erk1/2, anti-Akt (Protein kinase B), and antiphospho-Akt antibodies were purchased from Cell Signaling Technology (Beverly, MA, USA). Unless specifically stated, all other reagents were commercially purchased.

A172 (CRL-1620), U251, and U87-MG human GBM cells obtained from American Type Culture Collection (ATCC) and Shanghai Cell Bank of the Chinese Academy of Sciences (CAS) were maintained in a humidified incubator at $37{ }^{\circ} \mathrm{C}$ in a $5 \% \mathrm{CO}_{2}$ atmosphere in Dulbecco's modified Eagle's medium (DMEM, Gibco, Grand Island, NY, USA) supplemented with $10 \%$ fetal bovine serum (FBS, Gibco), and antibiotics (Gibco). Human dermal fibroblast (HDF) cells were primarily derived from the dermis of normal human adult skin and cultured in DMEM with 5\% FBS. HEK293T for lentiviral production were purchased from ATCC and cultured in DMEM supplemented with $10 \%$ FBS. Cells were passaged three times a week when confluent and only low passage cells (within passage 6) were used. 


\section{Immunocytochemistry and immunohistochemistry}

For immunocytochemistry, cells at passage 3-6 were cultured in DMEM with 10\% FBS for $24 \mathrm{~h}$. With $50 \%$ confluence, cells were fixed in $4 \%$ paraformaldehyde (PFA) and blocked with 0.5\% BSA (Bovine serum albumin) in PBST (Phosphate Buffered Saline with Tween 20). Cells were incubated with different primary antibodies at $4{ }^{\circ} \mathrm{C}$ overnight. Finally, rhodamine or FITC (Fluorescein isothiocyanate)-conjugated secondary antibodies were used for antibody localization and the nuclei were counter-stained with DAPI (4',6-diamidino-2phenylindole).

To validate the expression of SEPT9 and SEPT2 in gliomas, we analyzed human tissue arrays from 12 malignant GBM (Grade 4), 24 benign brain tumor (Grades 2-3), and 12 normal brain tissue samples, which were purchased from US Biomax Inc. (Rockville, MD, USA). For immunohistochemical staining, antigen retrieval and section staining methods were applied as previously described $^{41}$. Briefly, all samples were washed in xylene to remove the paraffin and then rehydrated through serial dilutions of alcohol. Treated sections were washed with phosphate-buffered saline (PBS) and then heated in a citrate buffer ( $\mathrm{pH}$ 6.0) for antigen retrieval. The samples were then incubated with anti-Septin antibody for $1 \mathrm{~h}$ at $37^{\circ} \mathrm{C}$. The conventional $\mathrm{ABC}$ peroxidase method (Vector, Burlingame, CA, USA) was performed for signal development and the cells were counter stained with hematoxylin. Negative controls were obtained by omitting the primary antibody.

\section{Construction of shRNA-expressing plasmid and viral production}

A pCDH-CMV-MCS-EF1-GreenPuro plasmid (SBI System Biosciences, Palo Alto, CA, USA) was used to construct the short hairpin RNA (shRNA)-expressing vector. The sequences listed in Supplementary Table S2 were inserted for SEPT9 and SEPT2 shRNA expression constructs. The viral production started by cotransfecting 293T cells with the shRNA expression vector and the packaging plasmids. After $48-72 \mathrm{~h}$, the media containing the viral particles were harvested and cellular debris was removed from the culture media by centrifugation. The pseudo-viral particles can be precipitated by centrifugation with PEG (Polyethylene glycol) for concentration before added to infect A172 or U87-MG cells.

\section{Gene expression analysis with qRT-PCR}

Total RNA from GBM cells was isolated using Trizol reagent (Thermo Fisher Scientific) for quantitative realtime PCR (qRT-PCR) analysis. Amplification reaction was performed with CFX96 real-time PCR detection system (Bio-Rad, Hercules, CA, USA) using SingleShot
SYBR Green qRT-PCR Kit according to the manual (Bio-Rad). The primers for SEPT9 and SEPT2 were listed in Supplementary Table S3 and relative gene expression was calculated using the $2^{-\Delta \Delta C}$ T method. All qRT-PCR experiments were performed in triplicates, and the data were normalized to the expression of GAPDH.

\section{Western blot analysis}

For western blot analysis, proteins were extracted in RIPA buffer (50 mM Tris-HCl, pH 7.4, 1\% Triton X-100, $0.25 \%$ sodium deoxycholate, $150 \mathrm{mM} \mathrm{NaCl}, 1 \mathrm{mM}$ EDTA, $0.1 \%$ sodium dodecyl sulfate (SDS) and a protease inhibitor cocktail) and separated by SDS-polyacrylamide gel electrophoresis (PAGE). The resolved proteins were transferred to PVDF (Polyvinylidene fluoride) membranes (Millipore). Nonspecific reactivity was blocked by incubating the membrane in $10 \mathrm{mM}$ Tris- $\mathrm{HCl}(\mathrm{pH}$ 7.5), 150 $\mathrm{mM} \mathrm{NaCl}, 2 \%$ Tween 20 and $4 \%$ bovine serum albumin 1 $\mathrm{h}$ at $37^{\circ} \mathrm{C}$. Diluted primary antibody was then added, followed by the appropriate secondary antibody. Protein detection was achieved with the enhanced chemiluminescence (ECL) system (Thermo Fisher Scientific). Relative protein level was calculated as a percentage of reference protein GAPDH.

\section{Cell proliferation and methyl thiazolyl tetrazolium (MTT) assay}

A172 and U87-MG cells at passage 3-4 were seeded into 96-well plates at 5000 cells per well. After infections with lentivirus as described above, on each day of consecutive 7 days, $10 \mu \mathrm{L}$ MTT $(5 \mathrm{mg} / \mathrm{mL})$ was added to each well and the cells were incubated at $37^{\circ} \mathrm{C}$ for additional 4 $\mathrm{h}$. Then, the supernatant was discarded and the reaction was terminated by lysing the cells with $100 \mu \mathrm{L}$ DMSO (Dimethyl sulfoxide). After 4-h incubation, optical absorption value at $570 \mathrm{~nm}$ was measured and the data were presented as the mean \pm standard deviation (SD), which were derived from triplicate samples of at least three independent experiments. In parallel, cell growth curve was also plotted with cell counting.

\section{Synergy determination}

The isobologram analysis for double knockdown of SEPT9 and SEPT2 was based upon the Chou-Talalay method to determine combination indices (CIs). The data obtained with the MTT assay were normalized to the Scramble control and expressed as \% viability. The data were then converted to Fraction affected ( $\mathrm{Fa}$; range $0-1$; where $\mathrm{Fa}=0$ represents $100 \%$ viability and $\mathrm{Fa}=1$ represents $0 \%$ viability) and analyzed with the CompuSyn program (Biosoft, Ferguson, MO) based upon the Chou and Talalay median effect principle ${ }^{42}$. The $\mathrm{CI}$ values reflect the ways of interaction between SEPT9 and SEPT2 
knockdown. $\mathrm{CI}<1$ indicates synergism, $\mathrm{CI}=1$ indicates an additive effect, and $\mathrm{CI}>1$ indicates antagonism.

\section{Wound-healing motility and transwell invasion assays}

Cell migration was determined using a wound-healing assay. A172 or U87-MG cells $\left(1 \times 10^{6} / \mathrm{mL} /\right.$ well $)$ at passage 3-4 were serum starved for $24 \mathrm{~h}$ and then seeded into sixwell plates and allowed to adhere for $12 \mathrm{~h}$. Confluent monolayer cells were scratched by a sterile $200-\mu \mathrm{L}$ pipette tip. The cells were washed with PBS to clear debris and suspension cells. Fresh serum-free medium with different lentiviral treatments were added, and the wounds were observed under a phase contrast microscope at 0 and $24 \mathrm{~h}$. Migration distance was calculated from the change in wound size during 24-h period using Image J software.

Cell invasion ability was measured using a transwell assay. Briefly, A172 or U87-MG cells $\left(5 \times 10^{4}\right)$ at passage 3-4 were suspended in serum-free medium with different lentivirus treatments. Transwell insert chambers (Corning Life Sciences, Corning, NY, USA) with $8-\mu \mathrm{m}$ pore filters were coated with a final concentration of $0.5 \mathrm{mg} / \mathrm{mL}$ Matrigel (BD Sciences, Bedford, MA, USA). Cells were seeded into the top chambers of the wells in $200-\mu \mathrm{L}$ media, and the lower chambers were filled with $600 \mu \mathrm{L}$ of $10 \%$ FBS media to induce cell invasion. After 24-h incubation, cells on the filter surface were fixed in 4\% PFA and examined under a fluorescence microscope, and the numbers of green cells were counted.

\section{Annexin V-7-AAD apoptosis assay}

Cell apoptosis was assessed by 7 -aminoactinomycin D (7-AAD) and Annexin V-PE double staining (BD Sciences). The treated cells were collected and washed three times with PBS, and then incubated in $200 \mu \mathrm{L}$ of staining solution containing Annexin V-PE (Phycoerythrin) antibody and 7-AAD for $15 \mathrm{~min}$ in the dark at room temperature. Cells at passage 4-5 were analyzed immediately on an Accuri C6 flow cytometer (Becton Dickinson, Mountain View, CA, USA) using CFlow Plus software. For each measurement, at least $2 \times 10^{4}$ cells were counted and the cell apoptosis rate was determined in three independent experiments.

\section{Flow cytometric analysis of the cell cycle}

Cell cycle analysis was performed using propidium iodide (PI) staining for DNA quantitation. Cells at passage 4-5 were harvested, washed and centrifuged at $1000 \mathrm{r} /$ min for $5 \mathrm{~min}$, and subsequently fixed in $70 \%$ ethanol at 4 ${ }^{\circ} \mathrm{C}$ for $>1 \mathrm{~h}$, followed by washing with PBS. Cells were then resuspended in $400 \mu \mathrm{L}$ PBS with $0.05 \%$ Triton $\mathrm{X}-100,0.1$ $\mathrm{mg} / \mathrm{mL}$ DNase-free RNase A, and $25 \mu \mathrm{g} / \mathrm{mL}$ PI and incubated for $30 \mathrm{~min}$ at $37^{\circ} \mathrm{C}$ in the dark. For each measurement, at least $2 \times 10^{4}$ cells were analyzed using an Accuri C6 flow cytometer. The cell cycle data were processed using ModFit LT 3.2 (Verity Software House, Topsham, ME, USA).

\section{Tumor growth assay in vivo}

Thirty-five-week-old female immune-deficient nude mice (BALB/c-nu) were purchased from Shanghai SLAC Laboratory Animal Company. The mice were maintained in the facility of laboratory animals, Hangzhou Normal University. The protocol for the experiment was approved, and animals were handled according to the ethical standards of the Institutional Animal Care and Use Committee of Hangzhou Normal University. The mice were assigned randomly to 1 of 5 groups for injection with Control, Scramble, SEPT9-sh, SEPT2-sh and SEPT2, 9-sh U87-MG cells. In all, $2 \times 10^{6}$ cells at passage 5-6 were injected subcutaneously into the right flank of the nude mice $^{43}$, which led to palpable nodules on day 5 . The GFP (Green fluorescent protein)-labeled GBM cells were traced with In Vivo Imaging System (PerkinElmer, San Jose, CA, USA), and the tumor volume was measured with calipers every 4 days through the observation period of 3 weeks, using the formula: Volume $=$ length $\times$ width $^{2} \times$ $0.5^{44}$. All the mice were sacrificed at day 21 and the tumor weights were measured.

\section{Statistics}

All experiments were performed in triplicate. Data were analyzed by SPSS12.0 and expressed as means \pm SD. Statistical comparisons between two groups were made using an unpaired Student's $t$-test and probability values $(p)<$ 0.05 were considered significant.

\section{Results}

Identification of SEPT9 and 2 as GBM associate genes by multi-omics analysis

To discover GBM associate genes, we combined GBM expression studies from the Gene Expression Omnibus (GEO) repository for a multiplex analysis. For each of the 47,000 transcripts tested, we calculated the Meta foldchange by taking a linear combination of effect sizes (foldchanges) weighted by the variance within each study, and the Meta $p$-values across all studies by using Fisher's $\operatorname{method}^{45}$. Significant genes were selected if the Meta fold-change is $>1.5$ and the Meta effect $p$-value was $<4.5 \times$ $10^{-5}$. This effort identified Notch1, SEPT9, SEPT2, NES, WEE1, RPN2, PDGFRB, SOX4, and others as GBM associate genes. We then filtered the candidates through a list of proteins derived from proteomic profiling of three different GBM cell lines, and further narrowed down SEPT9, SEPT2, WEE1, RPN2, and others as the final candidates (Fig. 1). We chose SEPT9 and SEPT2 for further validation as Septins have been implicated in cell proliferation, migration, and tumorgenesis but their roles in GBM have not been determined. 

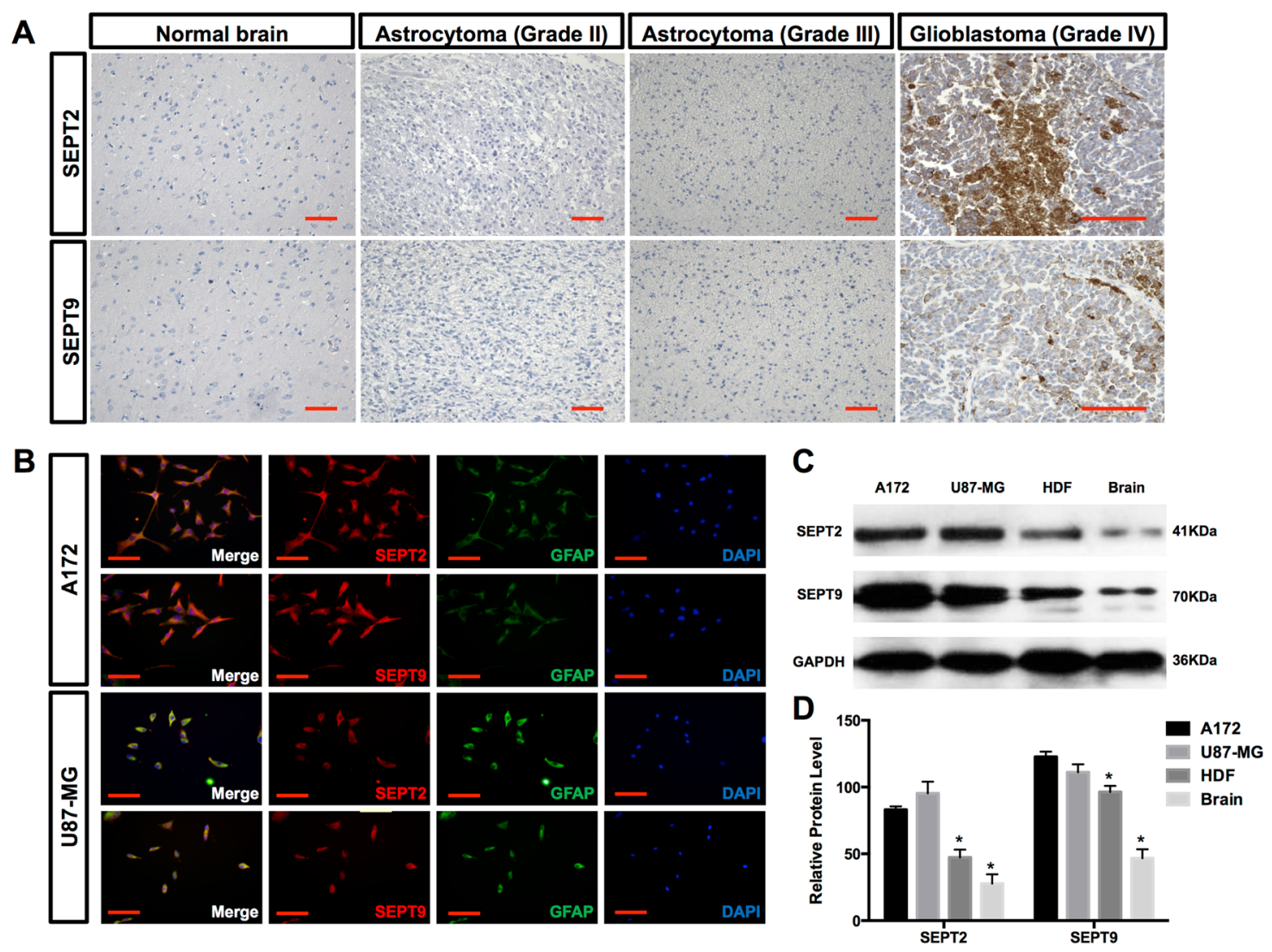

Fig. 2 Expression pattern of SEPT2 and SEPT9 in normal and glioma tissues and GBM cell lines. a The expression levels of SEPT2 and SEPT9 in 3 grades of gliomas and 12 normal brain tissues were detected by immunohistochemistry. SEPT2 and SEPT9 expression levels were much higher in GBM tissues than in the normal brain tissues, scale bar $=100 \mu \mathrm{m}$. b A172 and U87-MG cells stained for SEPT2 and SEPT9 showed a perinuclear as well as membrane-bound immunoreactivity colocalizing with GFAP, scale bar $=50 \mu \mathrm{m}$. c SEPT2 and SEPT9 expression levels in A172 and U87-MG are greater than that in HDF and normal brain tissues. $\mathbf{d}$ Quantitative analysis of the relative protein levels of SEPT2 and SEPT9 (percentage of GAPDH) from western blot $\left({ }^{*} p<0.05\right)$

\section{Expression of SEPT9 and SEPT2 in GBM tissues and cell} lines

To gain insight into the role of SEPT9 and SEPT2 in GBM, we first examined our multi-omics mining results in Oncomine database. The upregulated mRNA levels of SEPT9 and SEPT2 in GBM were validated in three independent studies (Supplementary Fig. S1A and S1B). In order to determine the potential clinical relevance of SEPT9 and SEPT2 genes, we analyzed TCGA RNA-Seq data set of GBM and found that their expression levels were significantly associated with unfavorable survival in patients with GBM (Fig. S1C and S1D). We further analyzed the expression of SEPT9 and SEPT2 in normal brain tissues $(n=12)$; low-grade glioma tissue samples (grade 2 , astrocytoma: $n=8$ ); grade 3 glioma samples (anaplastic astrocytoma: $n=12)$, and grade 4 , GBM $(n=12)$. Immunohistochemical analysis revealed the increased expression of SEPT9 and SEPT2 in grade 4 GBM tissues (Fig. 2a). The immunocytochemical and western blot analysis demonstrated increased expression levels of SEPT9 and SEPT2 in GBM cell lines (Fig. 2b), as compared with normal brain and HDF cells (Figs. 2c, d). Thus, SEPT9 and SEPT2 expression is upregulated in highgrade GBM tissues, as well as in several GBM-derived cell lines, such as A172 and U87-MG.

\section{Suppression of SEPT9 and SEPT2 expression using shRNA in $\mathrm{A} 172$ cells}

To study the roles of SEPT9 and SEPT2 in GBM, we selected two shRNA sequences each for SEPT9 (sh1, sh2) and SEPT2 (sh1, sh2) knockdown (Supplementary Table S2). As shown in Supplementary Fig. S2, SEPT9-sh1 and SEPT2-sh1 specifically downregulated the expression of SEPT9 and SEPT2, respectively. Accordingly, we generated the lentiviral expression vectors containing SEPT9sh1, SEPT2-sh1, and scramble (non-silencing sequence) controls for gene knockdown experiments. Suppression of SEPT9 and SEPT2 was verified by qRT-PCR (Fig. 3a) and 


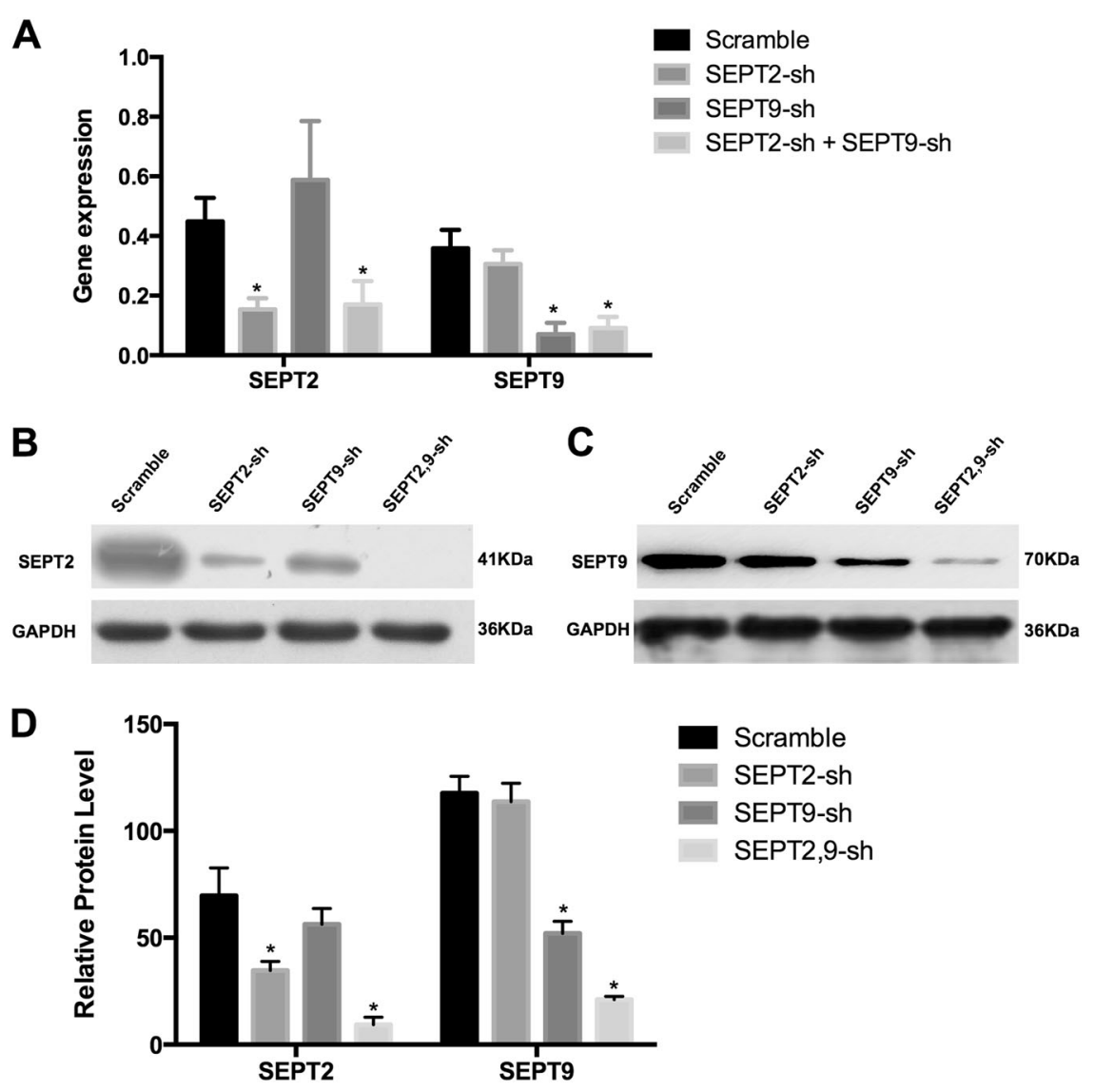

Fig. 3 Knocking-down of SEPT2 and SEPT9 mRNA reduced their protein levels. The efficacy of shRNA mediated stable knockdown against SEPT2 and SEPT9 mRNA a was verified by western blot with the protein levels in A172 cells. b, $\mathbf{c}$ The downregulated SEPT9 could slightly reduce the protein level of SEPT2, and vice versa. $\mathbf{d}$ Quantitative analysis of SEPT2 and SEPT9 levels relative to GAPDH as percentage from western blot $\left(^{*} p<0.05\right)$

western blot (Figs. 3b, c). Although SEPT9-sh1 and SEPT2-sh1 alone achieved $~ 50 \%$ inhibition of their respective genes, the combination of SEPT9-sh1 and SEPT2-sh1 achieved $~ 90 \%$ inhibition of both SEPT9 and SEPT2, suggesting their synergistic effect in repression of gene expression (Fig. 3d).

\section{Suppression of SEPT9 and SEPT2 synergistically reduced GBM cell viability}

The effects of SEPT9 and SEPT2 inhibition on GBM cell viability were examined in GBM cell line A172. Cells were transfected with the Scramble, SEPT2-sh, and SEPT9-sh expression vectors in which GFP is co-expressed (Fig. 4a). Along with Septin depletion and significant decrease in the number of cells, the shape of GBM cells changed remarkably as well. Scramble-treated cells seemed to have large cell bodies with long processes. SEPT2-sh-treated cells were relatively smaller and with thinner processes. Although SEPT9-sh and SEPT2, 9-sh-treated cells demonstrated a small and round shape (Fig. 4a). Furthermore, both SEPT9 and SEPT2 knockdown significantly inhibited A172 cell growth in a timedependent manner (Fig. 4b and Supplementary Fig. S3A). Among the various groups of RNAi inhibitions, the SEPT9-sh and SEPT2-sh combination exerted the strongest inhibition of cell growth in A172 cells, revealing their synergistic inhibitory effect (CI was 0.27-0.69, $\mathrm{CI}<1$ indicates synergism) with a Fa value of $0.10-0.98$ (Fig. 4c).

\section{SEPT9 and SEPT2 suppression arrested GBM cell cycle in the $S$ phase}

After verifying the anti-proliferation effect of SEPT9-sh and SEPT2-sh, the distribution of cell cycles was explored by flow cytometry. As shown in Fig. 5a, the A172 cells in G0/G1 phase were decreased sharply in both SEPT9-sh and SEPT2-sh group (from $86 \%$ to around 63\%), and there was no apparent difference between these two groups, although the combination group had the most reduction (from 86 to 58\%) than the single treatment groups (Fig. 5c). As a result, the $\mathrm{S}$ phase cells accumulated, and the G2/M phase cells disappeared. 

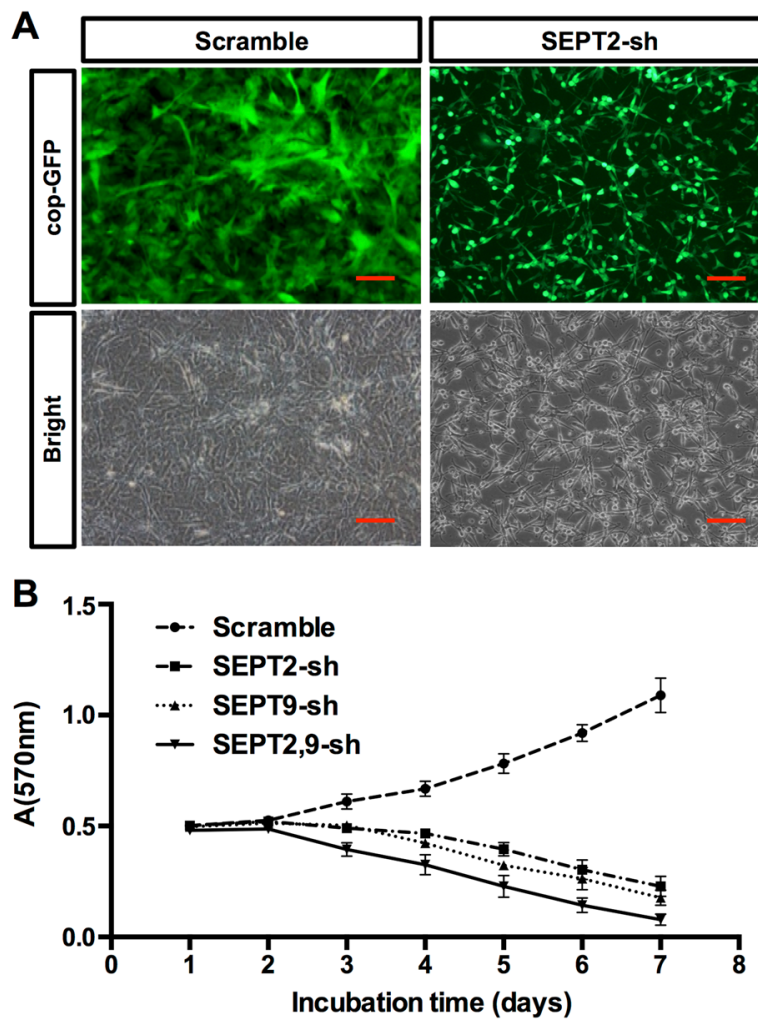
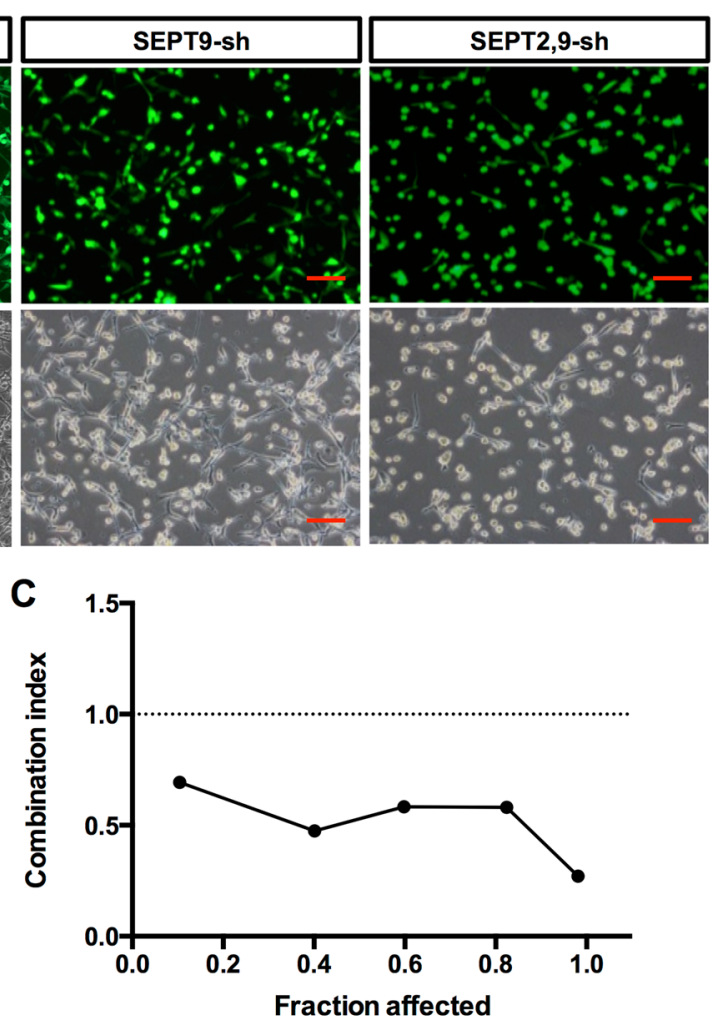

Fig. 4 ShRNA-mediated suppression of A172 cell growth in vitro. a Scramble control A172 cells, SEPT2 and SEPT9 shRNA-transfected cells and SEPT2, 9 shRNA co-transfected cells (GFP is co-expressed) were photographed under fluorescence microscope, scale bar $=100 \mu$ m. $\mathbf{b}$ Cell viability was measured using the MTT assay. Cell growth curves were determined by reading the absorbance at $570 \mathrm{~nm}$ on a multiscanner reader. c The synergistic effect between SEPT2-sh and SEPT9-sh was shown as Fa-Cl plot calculated with the CompuSyn software (Cl $<1$ indicates synergism, $\mathrm{Cl}=1$ indicates an additive effect, and $\mathrm{Cl}>1$ indicates antagonism)

\section{Downregulation of SEPT9 and SEPT2 expression induced GBM cell apoptosis}

To address whether the decreased cell number was attributable to apoptosis induced by SEPT9-sh and SEPT2sh, we compared cell death in A172 cells treated with various inhibitory RNAs. Although the scramble RNA produced $0.6 \pm 0.2 \%$ apoptotic cells, SEPT9-sh induced apoptosis in $58.4 \pm 3.8 \%$ of A172 cells, SEPT2-sh induced $71.4 \pm 6.0 \%$ and the combination of SEPT9-sh and SEPT2sh yielded $80.7 \pm 4.0 \%$ (dots in the lower right quadrant in Fig. 5b). Thus, knockdown of these two genes displayed a synergistic effect on inducing early apoptosis in A172 cells (Fig. 5d).

\section{SEPT9 and SEPT2 suppression synergistically inhibited migration and invasion of GBM cells in culture}

We next examined the effects of SEPT9 and SEPT2 suppression on the 2D-migration and 3D-invasion of GBM cells by wound-healing assay (Fig. 6a) and transwell assay (Fig. 6b). Wound-healing involves a number of processes, including cell proliferation, migration, and the establishment of cell polarity. To limit the impact of cell growth on our wound-healing assay, we starved the cells before and during the wounding assay of the monolayer cells. Serum starvation can result in a reversible cell cycle arrest at the G0/G1 phase ${ }^{46,47}$, and consequently the inhibition of cell growth. Meanwhile, the vast majority of GBM cells did not start cell growth within $48 \mathrm{~h}$ after seeding into plate as judged by the growth curve (Figs. $4 \mathrm{~b}$ and $7 \mathrm{~d}$ and Fig. S3A). As woundhealing and invasion assays were performed within $24 \mathrm{~h}$ when the cells were still at the resting phase, the decrease in the diameter of a wound reflected the result of migration only. As shown in Fig. 6a, the migration distances were significantly decreased after shRNA treatment. The SEPT2, 9-sh group had the shortest migration distance, and no obvious difference in migration was noticed between SEPT9-sh and SEPT2-sh group (Fig. 6c). The combined group exhibited the least migration and invasion ability, which was further confirmed by transwell assay (Fig. 6b). As cell invasion is an important feature of GBM cells, the decreased invasive cell numbers (from around 240 to 21) through transwell chamber membranes indicated that shRNA treatment reduced not 

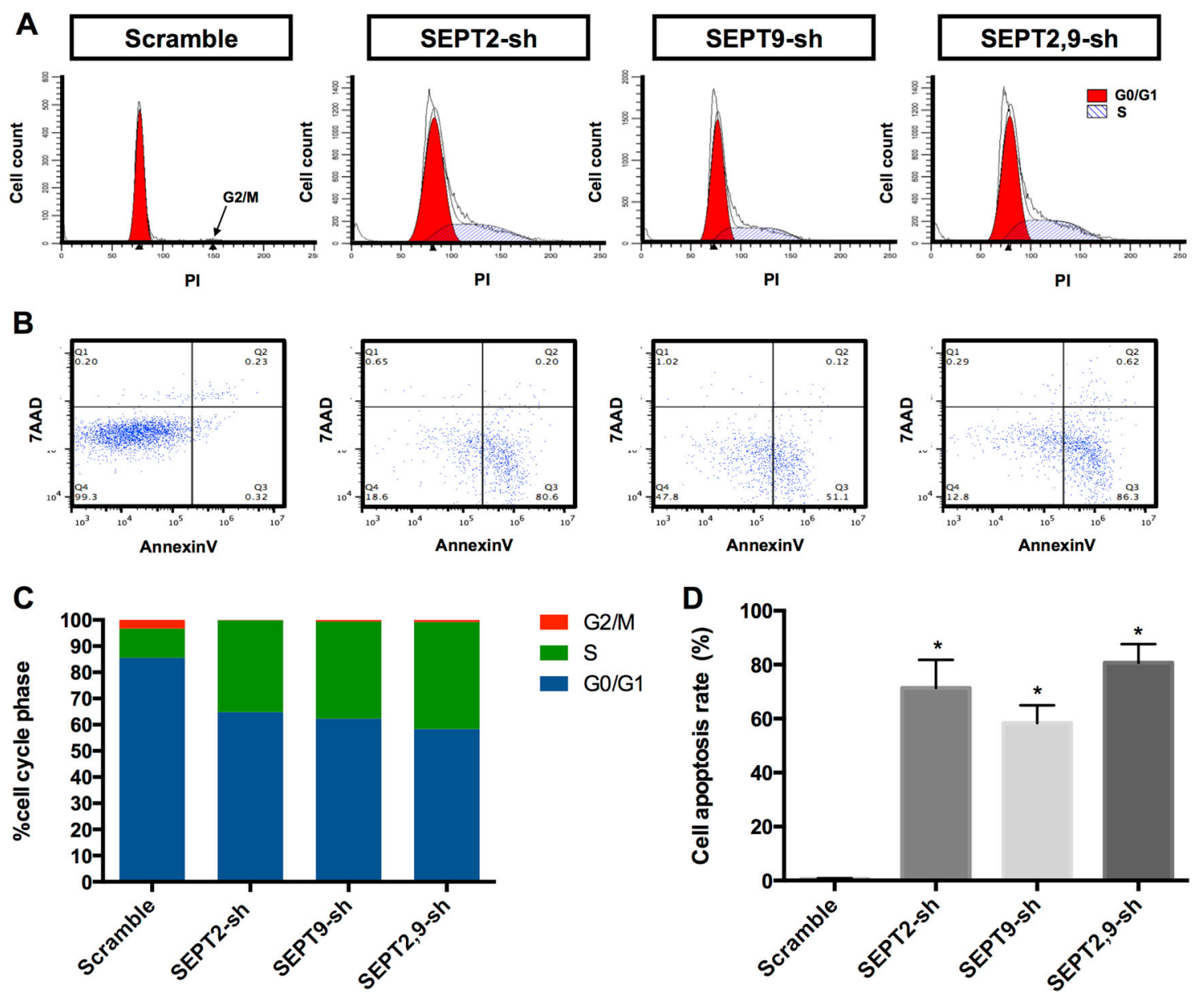

Fig. 5 Effects of knocking-down SEPT2 and SEPT9 on A172 cell cycle progression and cell apoptosis. a Cell cycle progression detected by FACS analysis. Cells in G0/G1 were marked in the red area. Cells in S phase were marked with blue slash, whereas the arrowhead indicated the G2/M cells. b Cell apoptosis was assessed with Annexin V-7-AAD staining. c Cell cycle distribution was calculated with ModFit LT software. The combination of SETP2-sh and SEPT9-sh had the most S phase cell accumulation (40.9\%). $\mathbf{d}$ The ratio of apoptotic cells in A172 cells treated with single shRNA was 71.4 or $58.4 \%$, respectively, whereas the ratio of apoptotic cells in double shRNA-treated group was $80.7 \%\left({ }^{*}, \mathrm{p}<0.05\right)$.

only the viability but also the motility of GBM cells (Fig. 6d).

\section{Suppression of SEPT9 and SEPT2 expression inhibited MEK-ERK activation and increased p53-p21 expression}

A recent study has reported that activation of MEKERK, but not PI3K (Targeting the phosphoinositide 3kinase)/AKT signaling pathway was correlated with the increased protein levels of SEPT2 and SEPT7 in breast cancer $^{29}$. Therefore, we set to investigate the molecular mechanisms underlying the SEPT9/2 RNAi-induced antiGBM effects. We observed that suppression of SEPT9 and SEPT2 specifically impaired MEK1/2 phosphorylation, and the phosphorylation of downstream Erk1/2 (Figs. 7a, e). There was no obvious increase in Akt activation, similar to the observation of SEPT2 and SEPT7 depletion in breast cancer cells (Supplementary Fig. S3B). This result implies that MEK-ERK axis might be pivotal to the functions of Septin family in different cancer cell types

As described earlier, SEPT9 and SEPT2 knockdown induced GBM cell cycle arrest in S phase (Figs. 5a, c) and massive cell apoptosis (Figs. 5b, d). Thus, we next examined the expression of cell cycle- and apoptosis-regulated protein p53 and p21. P53 protects mammals from neoplasia by inducing apoptosis, DNA repair, and cell cycle arrest in response to a variety of stresses ${ }^{48}$. As shown in Figs. 7b, e, p53 accumulated in single Septin knockdown groups and even more so in the double Septin knockdown group. Following p53 accumulation, the protein level of p21 was also upregulated, consistent with the previous observation that p53 could mediate the transcription of p21, which subsequently binds to the Cdc2-Cyclin B1 complex and inactivates it, leading to $\mathrm{S}$ phase cell cycle arrest. 
A

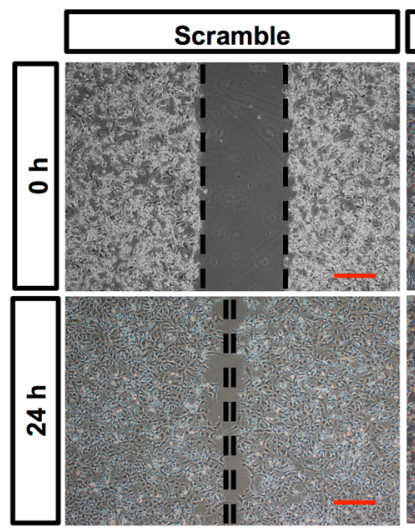

B
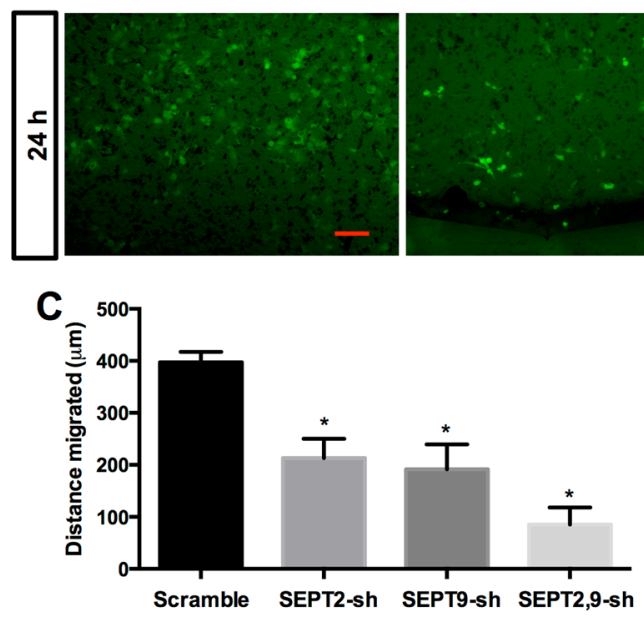
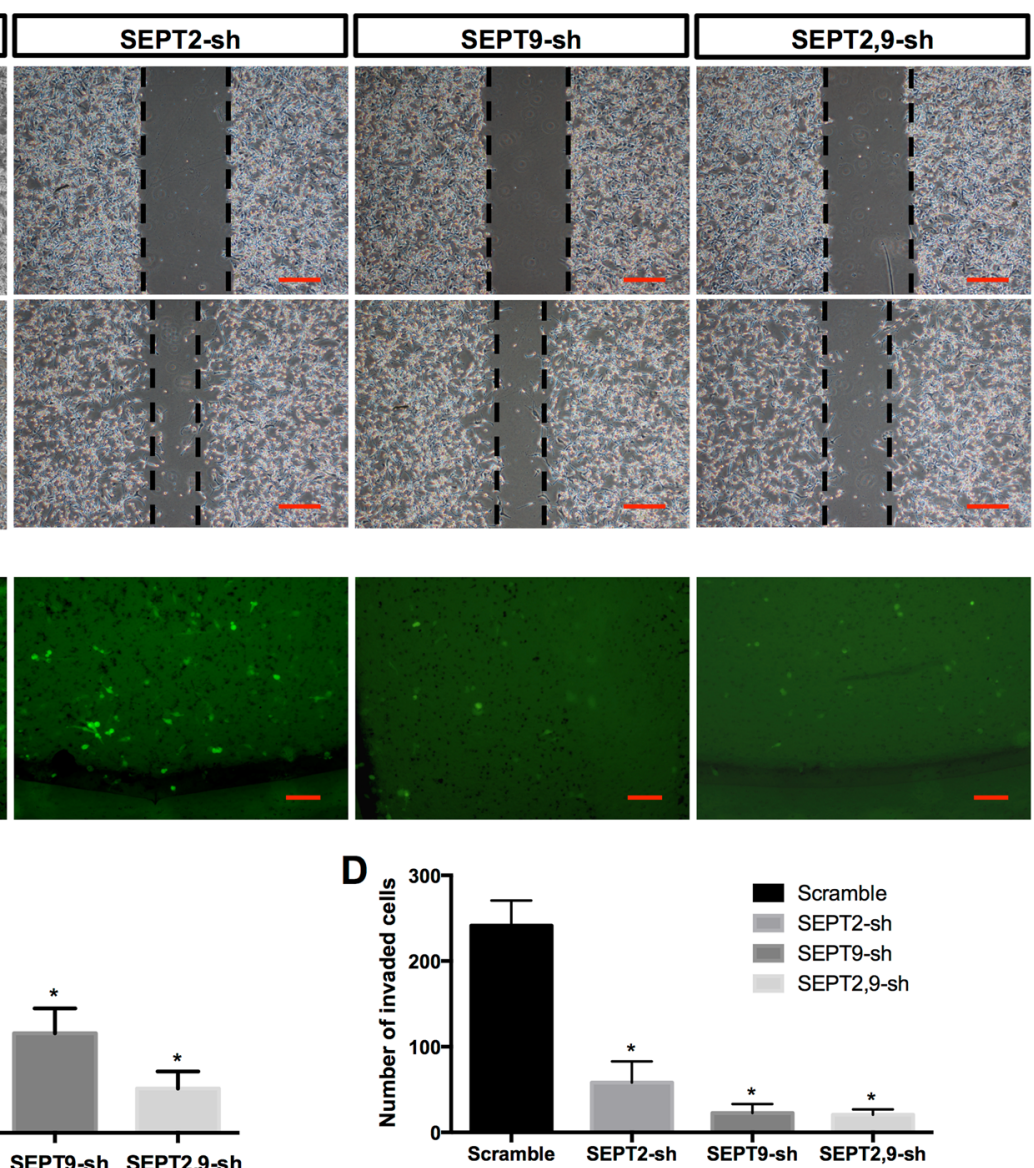

Fig. 6 Suppression of SEPT2 and SEPT9 modulated A172 cell migration and invasion. a Effects of SEPT2 and SEPT9 knockdown on A172 cell migration, scale bar $=100 \mu \mathrm{m}$. b SEPT2 and SEPT9 shRNA diminished cell invasion of A172 cells (Transwell assay with 8- $\mu \mathrm{m}$ pore size), scale bar $=100$ $\mu \mathrm{m}$. c The migration distance of A172 cells was quantified by Image J software with the SEPT2, 9-sh group having the shortest migration distance (85 $\mu \mathrm{m})$. $\mathbf{d}$ The mean cell counts of invading cells with the double knockdown group having the least invasion cells (around $21,{ }^{*} p<0.05$ )

\section{SEPT9 or SEPT2 overexpression rescued RNAi-induced cell growth inhibition}

As SEPT9 and SEPT2 knockdowns suppressed the GBM cell growth in a synergistic manner, we speculate that overexpression of one Septin gene could compensate for the loss of another in GBM cells. Thus, we performed the rescue experiment in A172 and U87 cells. As expected, overexpression of SEPT9 in SEPT2 knocked-down cells restored the cell growth (Fig. 7c). Conversely, overexpression of SEPT2 in SEPT9depleted cells had a similar effect in cell growth recovery (Fig. 7d). Interestingly, despite the full restoration of cell growth in both SEPT2 and SEPT9 rescued groups, the cells reshaped morphologically following RNAi treatments (Fig. 7c), suggesting that the effects of Septins on cell growth and cellular morphology depend on different mechanisms.

\section{Suppression of SEPT9 and SEPT2 inhibited GBM growth in vivo}

To investigate the anti-GBM effect of SEPT9 and SEPT2 RNAi in vivo, we established a subcutaneous xenograft tumor model of GBM cells. After RNAi treatment, U87, U87-Scramble, U87-SEPT2-sh, U87-SEPT9sh, and U87-SEPT2, 9-sh cells were injected into nude mice (Fig. 8a). Tumor volumes were measured at different time points of tumor growth in various groups (Fig. 8b). After 8 days, mice injected with U87-SEPT2-sh, U87SEPT9-sh, and U87-SEPT2, 9-sh cells did not show any increase in mean tumor size as compared with the U87 and U87-Scramble groups. After 20 days, tumors in each mouse were removed and weighed. Compared with control and scramble groups, both single and double Septin RNAi treatments significantly decreased the solid tumor mass (Fig. 8c), indicating that downregulating the 


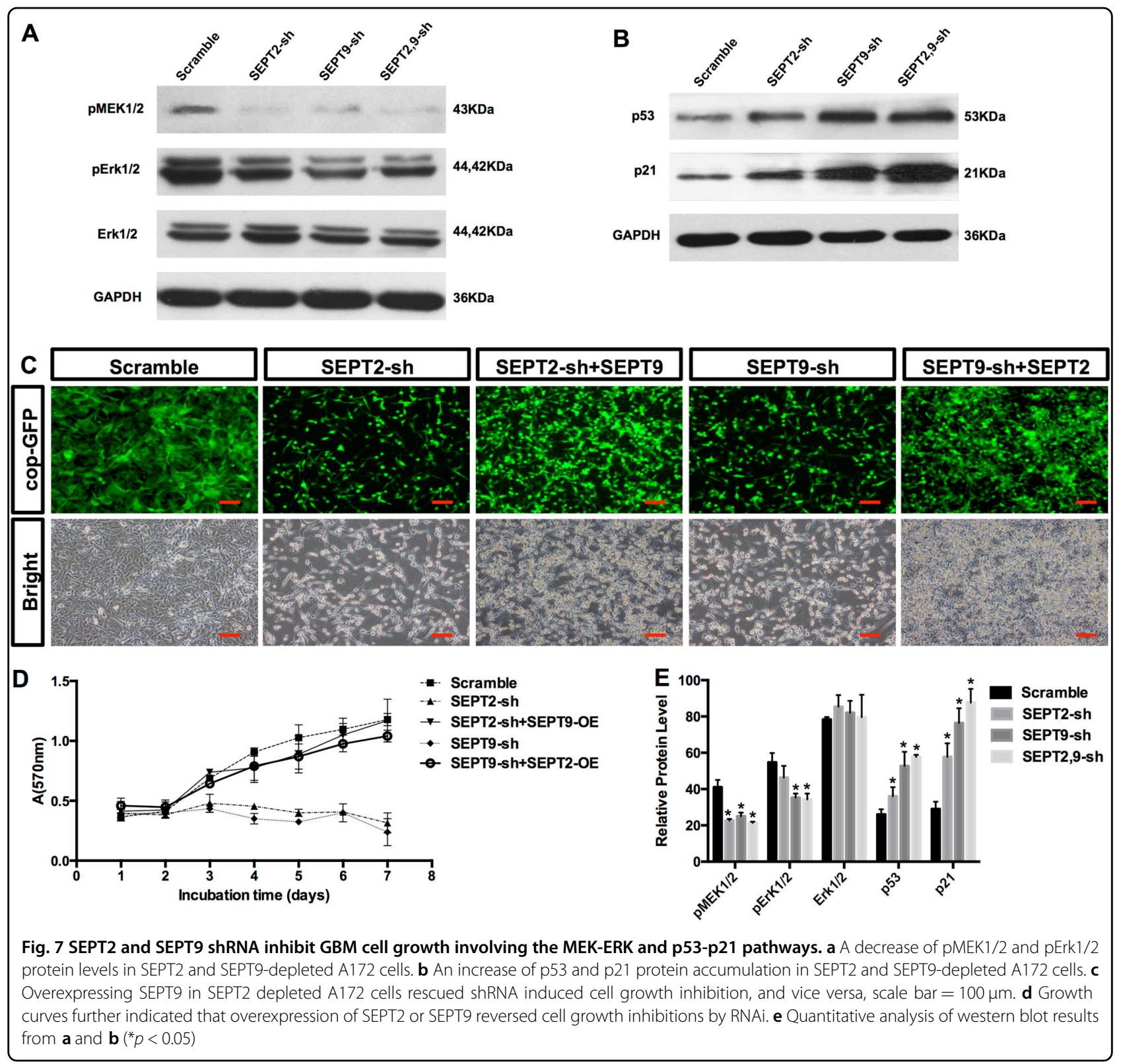

expression of SEPT9 and SEPT2 in GBM cells suppresses their tumor formation in vivo.

\section{Discussion}

Multi-omics approach increases confidence of SEPT9 and 2 as GBM associate genes

We have applied a multi-omics approach to developing a workflow from discovery of GBM-related candidates to validation of GBM functional molecules (Fig. 1). Through the integration of quantitative data from transcriptomics and proteomics, we have identified and validated SEPT9 and SEPT2 as potential targets for GBM treatment. SEPT9 and SEPT2 are two core elements of Septin family with similar cytosolic localization and biological functions (Fig. 2b), and have been implicated in a variety of human pathological conditions, including bacterial infection, Alzheimer disease, Parkinson disease, and male infertility ${ }^{49}$. SEPT9 was identified as an oncogene in ovarian, head and neck, and prostate cancer cells ${ }^{50-52}$. Moreover, promoter methylation of SEPT9 was considered as a specific and reliable biomarker for the early detection of colorectal cancer $^{53}$. SEPT2 downregulation was shown to suppress hepatoma and breast cancer cell growth ${ }^{29,36}$. Our study systematically investigated the functions of SEPT9 and SEPT2 in GBM tumorgenesis including tumor growth and invasion both in vitro and in vivo. 

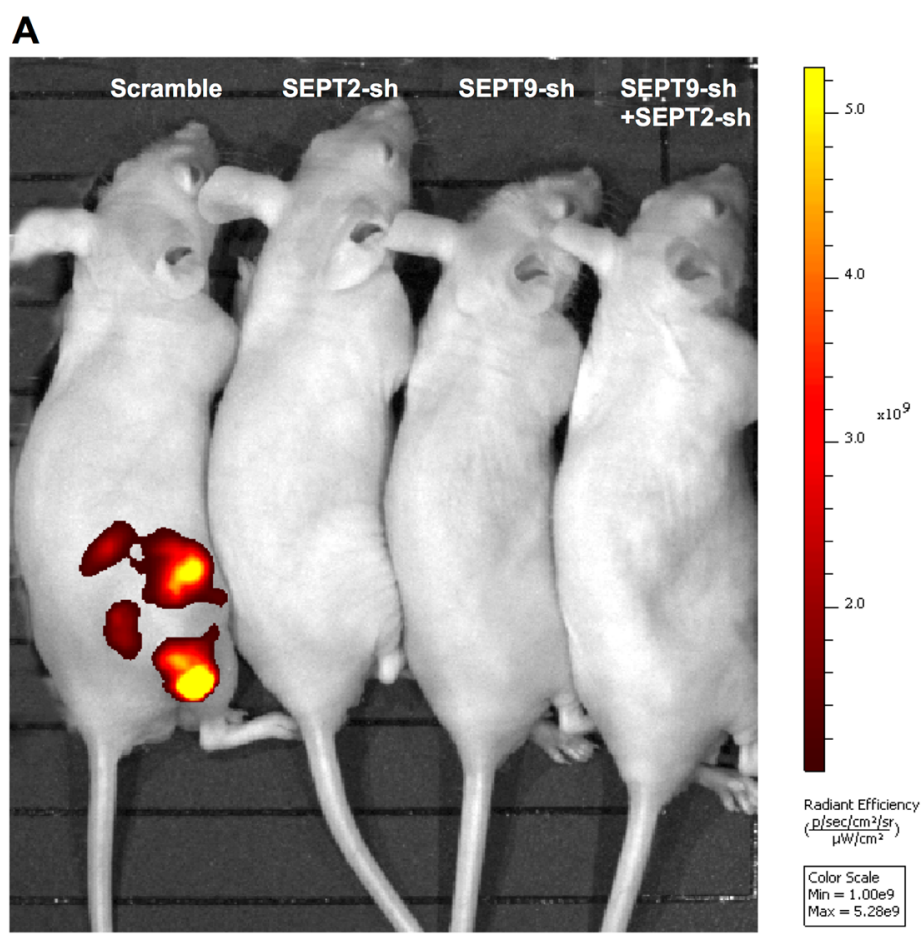

B
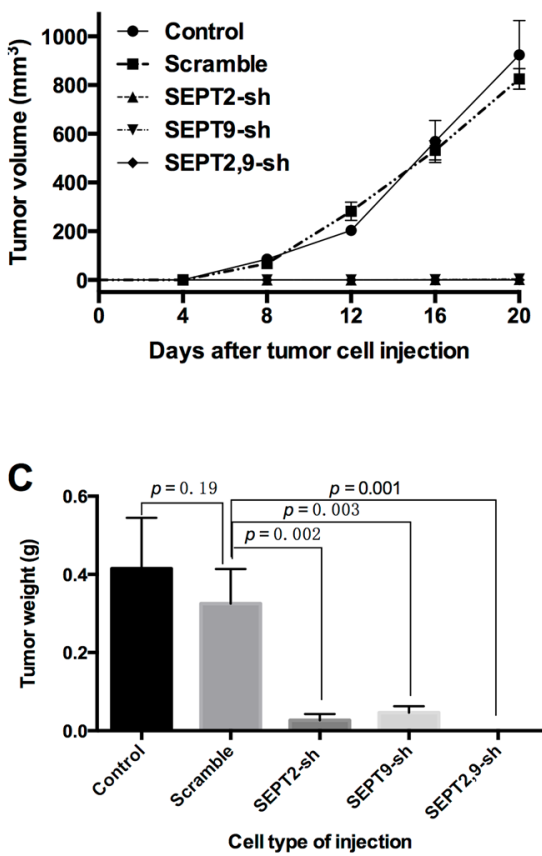

Fig. 8 Effects of SEPT2 and SEPT9 knockdown on GBM cell-derived subcutaneous xenograft tumors in nude mice. a The in vivo bioluminescent imaging data were analyzed in different groups via the IVIS system. $\mathbf{b}$ Quantitative analyses of the tumor progression. Tumor size was determined by measuring the tumor volume every 4 days from day 4 to day 20 after injection. c Tumor weights in mice 20 days after injection. Both single and double shRNA-treated groups demonstrated significant decrease of tumor weights $(p<0.05)$

\section{Combinatorial strategy with SEPT9 and 2 RNAi facilitates GBM therapy}

It is well established that combinatorial therapies consisting of anticancer drugs with different molecular targets result in synergistic effect that is generally more effective than monotherapy. Our findings that SEPT9 and SEPT2 shRNA synergistically restrained malignant behavior of GBM cells shed light on developing novel precision treatment of GBM with combinatorial RNAi. More importantly, we found that knockdown of SEPT9 and SEPT2 in normal human HDF cells did not disturb cell growth at all (Supplementary Fig. S3C), suggesting that SEPT9 and SEPT2 might have distinct functions in normal cell growth vs. tumor cell growth. It also implies that silencing SEPT9 and SEPT2 expression would be sufficient for GBM suppression with a minimum side effect.

\section{SEPT9 and 2 play roles opposite to SEPT7 in GBM cells}

Previous studies showed that overexpression of SEPT7 could suppress glioma cell growth and induce cell cycle arresting in the G0/G1 phase ${ }^{54-56}$. In contrast, our results indicate downregulation of SETP9 or SEPT2 inhibits GBM cell proliferation and arrests cell cycle in $S$ phase, suggesting the delicate and complex functional relationship among these three Septins in GBM. One key characteristic of Septins is their heterophilic interaction to form stable complex ${ }^{18,24}$. For example, SEPT9 can bind to SEPT2 and SEPT7 in a nonstoichiometric manner and stabilize the formation of higherorder complexes ${ }^{57}$. In support, we found that the silenced SEPT9 could slightly reduce the protein level of SEPT2, and vice versa (Figs. 3b, c). It is conceivable that the higher-order complex of SEPT9 and SEPT2 were able to protect or stabilize the single one from degradation ${ }^{58}$. This is also consistent with previous reports that knockdown of one Septin affects the protein level of another Septin from a different Septin subgroup $^{59,60}$.

The synergistic function of SEPT9 and 2 in GBM cells may involve two parallel pathways

From the perspective of downstream signal molecules, our findings demonstrate that knocking-down SEPT9 and SEPT2 synergistically upregulates the expression of p53 and p21 (Figs. 7b, e), which coordinate DNA repair, cell cycle control, or apoptosis initiation. It is not clear whether SEPT9 and SEPT2 could act on p53/p21 pathway directly or through an intermediate factor. It was reported that overexpression of SEPT7 inhibits glioma cell proliferation and arrests cell cycle progression by upregulation of $\mathrm{p} 21^{54}$. It is plausible that SEPT9-SEPT7-SEPT2 
complex might arrest SEPT7 and suppress its upregulation of p21 expression, and subsequently promote tumor growth. This might also explain the synergistic effect of silenced SEPT9 and SEPT2 simultaneously in GBM.

Our results also showed that knockdown of SEPT9 or SEPT2 in GBM cells reduces the activation of MEK/ERK pathway (Figs. 7a, e), which contributes to GBM cell proliferation, migration, invasion, and tumor formation in vivo $^{61}$. Although MEK1/2 phosphorylation was impaired, levels of phospho-Akt stimulated by the activation of PI3K/AKT pathway remained the same (Fig. S3B). These results suggest that both SEPT9 and SEPT2 promote the GBM malignancy by activating the MEK/ ERK, but not the PI3K/AKT pathway. Therefore, two parallel pathways (p53/p21 and MEK/ERK) are likely to be involved in the SEPT9 and SEPT2 regulation of GBM cell proliferation. Considering that Septins are cytoskeletal proteins $^{19,27}$, it is also conceivable that they enhance GBM migration and invasion by interacting with actin, tubulin and myosin. In support, knocking-down SEPT9 and SEPT2 not only reduced the motility of GBM cells but also reshaped the cells morphologically (Fig. 4a).

\section{Possible compensatory mechanisms in SEPT2 and SEPT9}

Our results showed that SEPT2 and SEPT9 could compensate each other in cell growth rescue experiments (Figs. 7c, d). The compensatory mechanisms for SEPT2 and SEPT9 are not known at this stage. It has been suggested that four Septin family members (SEPT2, 3, 6, 7) can form typical heterohexamer SEPT7-6-2-2-6-7 or hetero-octamer SEPT9-7-6-2-2-6-7-9, which then form higher-order structures such as filaments and rings ${ }^{19}$. In view of this finding, it is possible that overexpression of SEPT2 in SEPT9 knocked-down cells might increase the production of heterohexamers SEPT7-6-2-2-6-7, which can compensate for the loss of SEPT9. Recently, Kuo et al. reported that SEPT4 could occupy the same position as $\mathrm{SEPT}^{62}$, and therefore overexpression of SEPT9 in SEPT2 knocked-down cells might induce the expression of SEPT4, and compensate for the loss of SEPT2.

\section{Conclusion}

In summary, our study demonstrated that SEPT9 and SEPT2 are essential for GBM cell proliferation, migration, and invasion by controlling MEK/ERK activation and p53/ p21 expression. SEPT9 and SEPT2 knockdown by RNAi in GBM cells exerts a synergistic antitumor effect. These findings suggest that the Septin proteins might be novel targets for GBM treatment.

\section{Acknowledgements}

This work was supported by grants from Zhejiang Province Medical and Health Research Program (2013KYA148), high-level students returning to China (team) project in Hangzhou (2017), Zhejiang Provincial Natural Science Foundation of
China (no. LQ18C090009), and National Natural Science Foundation of China (81200961, 31471955, 31572224, 31771621).

\section{Author details}

${ }^{1}$ Institute of Life Sciences, Key Laboratory of Organ Development and Regeneration of Zhejiang Province, College of Life and Environmental Sciences, Hangzhou Normal University, Zhejiang 311121, China. ${ }^{2}$ Institute of Cognitive Neuroscience and Department of Psychology, Zhejiang Sci-Tech University, Hangzhou, China. ${ }^{3}$ Department of Anatomical Sciences and Neurobiology, University of Louisville, Louisville, KY 40292, USA

Conflict of interest

The authors declare that they have no conflict of interest.

\section{Publisher's note}

Springer Nature remains neutral with regard to jurisdictional claims in published maps and institutional affiliations.

Supplementary Information accompanies this paper at (https://doi.org/ 10.1038/s41419-018-0547-4).

Received: 25 October 2017 Revised: 27 March 2018 Accepted: 27 March 2018

Published online: 03 May 2018

\section{References}

1. Omuro, A. \& DeAngelis, L. M. Glioblastoma and other malignant gliomas: a clinical review. JAMA 310, 1842-1850 (2013).

2. Dolecek, T. A., Propp, J. M., Stroup, N. E. \& Kruchko, C. CBTRUS statistical report: primary brain and central nervous system tumors diagnosed in the United States in 2005-2009. Neuro-Oncology 14, v1-v49 (2012). Suppl 5.

3. Louis, D. N. et al. The 2016 World Health Organization Classification of Tumors of the Central Nervous System: a summary. Acta Neuropathol. 131, 803-820 (2016).

4. Bianco, J. et al. On glioblastoma and the search for a cure: where do we stand? Cell. Mol. Life. Sci. 74, 2451-2466 (2017).

5. Walid, M. S. Prognostic factors for long-term sunvival after glioblastoma. Perm. J. 12, 45-48 (2008)

6. Fan, Q. W. et al. Akt and autophagy cooperate to promote survival of drugresistant glioma. Sci. Signal. 3, ra81 (2010).

7. Bao, S. et al. Glioma stem cells promote radioresistance by preferential activation of the DNA damage response. Nature 444, 756-760 (2006).

8. Parsons, D. W. et al. An integrated genomic analysis of human glioblastoma multiforme. Science 321, 1807-1812 (2008).

9. Reddy, S. P. et al. Novel glioblastoma markers with diagnostic and prognostic value identified through transcriptome analysis. Clin. Cancer Res. 14, 2978-2987 (2008).

10. Yan, $Y$. et al. LncRNA and mRNA interaction study based on transcriptome profiles reveals potential core genes in the pathogenesis of human glioblastoma multiforme. J. Cancer Res. Clin. Oncol. 141, 827-838 (2015).

11. Holland, E. C. Glioblastoma multiforme: the terminator. Proc. Natl. Acad. Sci. USA 97, 6242-6244 (2000).

12. Zhang, G., Huang, S. \& Wang, Z. A meta-analysis of bevacizumab alone and in combination with irinotecan in the treatment of patients with recurrent glioblastoma multiforme. J. Clin. Neurosci. 19, 1636-1640 (2012).

13. Efferth, T., Ramirez, T., Gebhart, E. \& Halatsch, M. E. Combination treatment of glioblastoma multiforme cell lines with the anti-malarial artesunate and the epidermal growth factor receptor tyrosine kinase inhibitor OSI-774. Biochem. Pharmacol. 67, 1689-1700 (2004).

14. Doherty, L. et al. Pilot study of the combination of EGFR and mTOR inhibitors in recurrent malignant gliomas. Neurology 67, 156-158 (2006).

15. Friedman, H. S. et al. Bevacizumab alone and in combination with irinotecan in recurrent glioblastoma. J. Clin. Oncol. 27, 4733-4740 (2009).

16. Hartwell, L. H., Culotti, J., Pringle, J. R. \& Reid, B. J. Genetic control of the cell division cycle in yeast. Science 183, 46-51 (1974).

17. Weirich, C. S., Erzberger, J. P. \& Barral, Y. The septin family of GTPases: architecture and dynamics. Nat. Rev. Mol. Cell Biol. 9, 478-489 (2008). 
18. Martinez, C., Sanjuan, M. A., Dent, J. A., Karlsson, L. \& Ware, J. Human septinseptin interactions as a prerequisite for targeting septin complexes in the cytosol. Biochem. J. 382, 783-791 (2004).

19. Mostowy, S. \& Cossart, P. Septins: the fourth component of the cytoskeleton. Nat. Rev. Mol. Cell Biol. 13, 183-194 (2012).

20. Longtine, M. S. et al. The septins: roles in cytokinesis and other processes. Curr. Opin. Cell Biol. 8, 106-119 (1996).

21. Kartmann, B. \& Roth, D. Novel roles for mammalian septins: from vesicle trafficking to oncogenesis. J. Cell Sci. 114, 839-844 (2001).

22. Kinoshita, M. Assembly of mammalian septins. J. Biochem. 134, 491-496 (2003).

23. Macara, I. G. et al. Mammalian septins nomenclature. Mol. Biol. Cell 13, 4111-4113 (2002).

24. Neubauer, K. \& Zieger, B. The mammalian septin interactome. Front. Cell Dev. Biol. 5, 3 (2017)

25. $\mathrm{Hu}, \mathrm{Q}$. et al. A septin diffusion barrier at the base of the primary cilium maintains ciliary membrane protein distribution. Science 329, 436-439 (2010).

26. Spiliotis, E. T., Kinoshita, M. \& Nelson, W. J. A mitotic septin scaffold required for Mammalian chromosome congression and segregation. Science $\mathbf{3 0 7}$, 1781-1785 (2005)

27. Kremer, B. E., Adang, L. A. \& Macara, I. G. Septins regulate actin organization and cell-cycle arrest through nuclear accumulation of NCK mediated by SOCS7. Cell 130, 837-850 (2007).

28. Connolly, D., Abdesselam, I., Verdier-Pinard, P. \& Montagna, C. Septin roles in tumorigenesis. Biol. Chem. 392, 725-738 (2011).

29. Zhang, N. et al. The requirement of SEPT2 and SEPT7 for migration and invasion in human breast cancer via MEK/ERK activation. Oncotarget 7, 61587-61600 (2016)

30. Froidevaux-Klipfel, L. et al. Septin cooperation with tubulin polyglutamylation contributes to cancer cell adaptation to taxanes. Oncotarget 6, 36063-36080 (2015).

31. Froidevaux-Klipfel, L. et al. Modulation of septin and molecular motor recruitment in the microtubule environment of the Taxol-resistant human breast cancer cell line MDA-MB-231. Proteomics 11, 3877-3886 (2011).

32. Wasserkort, R. et al. Aberrant septin 9 DNA methylation in colorectal cancer is restricted to a single CpG island. BMC Cancer 13, 398 (2013).

33. Connolly, D. et al. Septin 9 isoform expression, localization and epigenetic changes during human and mouse breast cancer progression. Breast Cancer Res.13, R76 (2011)

34. Russell, S. E. et al. Isolation and mapping of a human septin gene to a region on chromosome 17q, commonly deleted in sporadic epithelial ovarian tumors. Cancer Res. 60, 4729-4734 (2000).

35. Bennett, K. L. et al. Frequently methylated tumor suppressor genes in head and neck squamous cell carcinoma. Cancer Res. 68, 4494-4499 (2008).

36. Cao, L. Q. et al. Activation of peroxisome proliferator-activated receptorgamma (PPARgamma) inhibits hepatoma cell growth via downregulation of SEPT2 expression. Cancer Lett. 359, 127-135 (2015).

37. Griesinger, A. M. et al. Characterization of distinct immunophenotypes across pediatric brain tumor types. J. Immunol. 191, 4880-4888 (2013).

38. Gravendeel, L. A. et al. Intrinsic gene expression profiles of gliomas are a better predictor of survival than histology. Cancer Res. 69, 9065-9072 (2009).

39. Grzmil, M. et al. MAP kinase-interacting kinase 1 regulates SMAD2-dependent TGF-beta signaling pathway in human glioblastoma. Cancer Res. $\mathbf{7 1}$ 2392-2402 (2011).

40. Sun, L. et al. Neuronal and glioma-derived stem cell factor induces angiogenesis within the brain. Cancer Cell 9, 287-300 (2006).

41. Tan, Z. et al. Production of rabbit monoclonal antibodies against mouse embryonic stem cells and identification of pluripotency-associated surface antigens. J. Immunol. Methods 365, 149-157 (2011).
42. Chou, T. C. Theoretical basis, experimental design, and computerized simulation of synergism and antagonism in drug combination studies. Pharmacol. Rev. 58, 621-681 (2006)

43. Sun, C. et al. Antisense MMP-9 RNA inhibits malignant glioma cell growth in vitro and in vivo. Neurosci. Bull. 29, 83-93 (2013).

44. Naito, S., von Eschenbach, A. C., Giavazzi, R. \& Fidler, I. J. Growth and metastasis of tumor cells isolated from a human renal cell carcinoma implanted into different organs of nude mice. Cancer Res. 46, 4109-4115 (1986).

45. Morgan, A. A., Khatri, P., Jones, R. H., Sarwal, M. M. \& Butte, A. J. Comparison of multiplex meta analysis techniques for understanding the acute rejection of solid organ transplants. BMC Bioinform. 11, S6 (2010). Suppl 9.

46. Chen, $M$. et al. Serum starvation induced cell cycle synchronization facilitates human somatic cells reprogramming. PLOS ONE 7, e28203 (2012).

47. Tong, J. et al. Serum starvation and thymidine double blocking achieved efficient cell cycle synchronization and altered the expression ofp27, p53, bcl-2 in canine breast cancer cells. Res. Vet. Sci. 105, 10-14 (2016).

48. Taylor, W. R. \& Stark, G. R. Regulation of the G2/M transition by p53. Oncogene 20, 1803-1815 (2001).

49. Peterson, E. A. \& Petty, E. M. Conquering the complex world of human septins: implications for health and disease. Clin. Genet. 77, 511-524 (2010).

50. Scott, M. et al. Multimodality expression profiling shows SEPT9 to be overexpressed in a wide range of human tumours. Oncogene 24, 4688-4700 (2005).

51. McDade, S. S., Hall, P. A. \& Russell, S. E. Translational control of SEPT9 isoforms is perturbed in disease. Human. Mol. Genet. 16, 742-752 (2007).

52. Gilad, R. et al. High SEPT9 i1 protein expression is associated with high-grade prostate cancers. PLOS ONE 10, e0124251 (2015).

53. Lofton-Day, C. et al. DNA methylation biomarkers for blood-based colorectal cancer screening. Clin. Chem. 54, 414-423 (2008).

54. Jia, Z. F. et al. Overexpression of septin 7 suppresses glioma cell growth. J. Neuro-Oncol. 98, 329-340 (2010).

55. Yue, X. et al. MiR-301a is activated by the Wnt/beta-catenin pathway and promotes glioma cell invasion by suppressing SEPT7. Neuro-Oncology $\mathbf{1 8}$, 1288-1296 (2016)

56. Jiang, $\mathrm{H}$. et al. MicroRNA-127-3p promotes glioblastoma cell migration and invasion by targeting the tumor-suppressor gene SEPT7. Oncol. Rep. 31, 2261-2269 (2014).

57. Diesenberg, K., Beerbaum, M., Fink, U., Schmieder, P. \& Krauss, M. SEPT9 negatively regulates ubiquitin-dependent downregulation of EGFR. J. Cell Sci. 128, 397-407 (2015).

58. Valadares, N. F., d' Muniz Pereira, H., Ulian Araujo, A. P. \& Garratt, R. C. Septin structure and filament assembly. Biophys. Rev. 9, 481-500 (2017).

59. Sellin, M. E., Sandblad, L., Stenmark, S. \& Gullberg, M. Deciphering the rules governing assembly order of mammalian septin complexes. Mol. Biol. Cell 22 3152-3164 (2011)

60. Peng, X. R., Jia, Z., Zhang, Y., Ware, J. \& Trimble, W. S. The septin CDCrel-1 is dispensable for normal development and neurotransmitter release. Mol. Cell. Biol. 22, 378-387 (2002)

61. Friday, B. B. \& Adjei, A. A. Advances in targeting the Ras/Raf/MEK/Erk mitogenactivated protein kinase cascade with MEK inhibitors for cancer therapy. Clinical cancer research: an official journal of the American Association for. Cancer Res. 14, 342-346 (2008).

62. Kuo, Y. C. et al. SEPT12 orchestrates the formation of mammalian sperm annulus by organizing core octameric complexes with other SEPT proteins. $J$. Cell Sci. 128, 923-934 (2015). 